\title{
Verb Valency in Listening Comprehension Practice of the TOEFL Test
}

\author{
Sisila Fitriany Damanik ${ }^{1 *}---$ Mulyadi $^{2}$ \\ ${ }^{\prime}$ Universitas Negeri Medan, Indonesia. \\ Email:sfdamanik@gmail.com \\ ${ }^{2}$ Universitas Sumatera Utara, Indonesia.
}

\begin{abstract}
This article is about verb valences which discuss the link of elements in language. It is the relationship between verbs and elements or constituents around them in their capacity as basic constituents of building sentences. The basic constituents include the transitivity and verb assignment to the surrounding arguments so that there are one-valent (monovalency), twovalent (bivalency) and even three-valent (trivalency) forms found. The data analysis method used is a referential equivalent method with the basic technique of powering it to differentiate referents. The basic technique used is the technique of determining the determinant elements by powering them to differentiate the referents. This technique is used to sort or classify the valency structure of verbs in the matter of Listening Comprehension practice of the TOEFL test. The source of data is from The Complete Guide to the TOEFL Test written by Bruce Rogers. As the result, there are verb with one, two and three valences. A mono-valent verb in a sentence or clause is a verb form which is only compounded with one dependent element and is the subject of that clause. The verbs with two valences are also found in the exercise. The verbs that can bind two arguments at once and usually the argument is the subject and grammatical object of the sentence, and both must be attached simultaneously. A three-valent verb appears in a sentence or clause that has a syntactic / periphrasis causative construction.
\end{abstract}

Keywords: Valency, Monovalency, Bivalency, Trivalency.

Licensed: This work is licensed under a Creative Commons Attribution 4.o License.

Funding: This study received no specific financial support.

Competing Interests: The authors declare that they have no competing interests.

Acknowledgement: The authors would like to acknowledge the contribution of those involved in the finishing of this article

\section{Introduction}

Essentially, the term valency or valence is used in chemical terminology as a statement about the capacity of elements combined with other chemical elements. Likewise, in linguistics, the term valency is also used to express the relationship of compounding elements in a chemical compound, but in linguistics the compound element is the compounding of clauses or sentences building elements in a language intended to provide syntactic relationships (Whaley, 1997). Valency of verbs of all languages, basically, can be described the form of existence and its compounds with verbs that are compounded or bound to it. This compounding is universal for all languages in the world.

The link of elements in language is the relationship between verbs and elements or constituents around them in their capacity as basic constituents of building sentences, namely grammatical subjects and objects which are attached to or combined with these verbs. The basic constituents include the transitivity and verb assignment to the surrounding arguments so that there are one-valent (monovalency), two-valent (bivalency) and even three-valent (trivalency) forms found. 
In verb valency, there are two forms of verb assignments - transitive and intransitive verbs forms. Although it seems that these two forms are the same, but in fact they are indeed completely different. The term transitive and intransitive refer to the presence or absence of a combination of verbs with a subject or grammatical object that can be attached to it. Although the terms transitive and valency are different, the use of the term transitive is still needed in this discussion of valency because the use of the term transitive is caused by the existence of relations with matters concerning the subject and grammatical objects in clauses or sentences.

In this article, the valency of the verbs which will be analyzed is the valency of the verbs in Listening Comprehension practice of the TOEFL test. As McNamara (2000) said, when someone has reached the aspects of a language, and combines these aspects with their language skills, we can measure how great they are with language tests. Language tests can be accepted to determine someone's language skills as long as they are appropriate with the tests chosen. The TOEFL test is one of the standard language proficiency tests that measures a person's skills in language. The fame of this test increases with the number of English language students who use English as a foreign language.

If Setyawan and Wiratmaja (2018) analyze the TOEFL test in semantic and pragmatic contexts, and they find several types of semantics and pragmatics on the test, then in this article the author will analyze valency verb aspects as objects of study that are expected to help students or the community in studying the TOEFL test as a standard language proficiency test.

The problems that will be discussed in this study relate to the valency structure of verbs in the Listening Comprehension practice of TOEFL test.

\section{Literature Review}

Aisen in Hopper and Thompson (1982) suggests that valency is used to refer to the nominal number of arguments in a clause at any level. While Katamba (1993) states that valency is the number of arguments in the syntactic framework associated with verbs caused by grammatical functions. The same thing was declared by Van Vallin and LaPolla (2002) - the number of capable and common arguments bound or taken by verbs is called valency. They distinguish between valency syntax verbs and valency semantic verbs. Valency of syntax verb is the number of arguments morphosyntactically implied and it is needed by the verb. Meanwhile, the valency semantic verb is the number of semantic arguments taken by certain verbs. Both types of valency are somewhat different. The word rain in English, for example, does not require an argument semantically, but syntactically the word requires one argument because each English clause requires a subject, for example, It rained or It is raining. In English, the clause Rained or Is training is not acceptable because those clauses have no argument.

Furthermore, the notion of valency is generally associated with transitivity. Herbert in Hopper and Thompson (1982) alludes to the issue of transitivity structurally and traditionally. According to him, structural transparency is a structure related to a predicate and two non-oblique arguments; Subject (S) and Direct Object (DO). Traditional transitivity is overall transitive in clause; refers to bringing or moving actions from agent to patient. Basically, valency is determined by verb behavior. Therefore, the verb can be called a transitive verb (intransitive, transitive and ditransitive).

Transitivity can also be seen and understood as the number of components relating to the different aspects of the effectiveness or intensity with which action is carried out (see Hopper and Thompson, 1982). The study of valency (syntax) which is equated with transitivity is also stated by Van Vallin and La Polla (2002) in which they stated that verbs which take one core argument in syntax are called intransitive verbs, which take two arguments called transitive, and which takes three arguments called ditransitive. This is in line with the opinion of Verhaar (2012) which explains that verbs in languages can be verbs that have one two or three valences. Verbs with one valency are marked with verb forms which can only be compounded or followed by just one argument. Furthermore, the verb which has two valences are the verbs that can bind two arguments at the same time. Then the three-dimensional verb is a verb that can bind three arguments at once. The abbreviations used in this article are:

\begin{tabular}{l|l}
\hline Abreviation & Original Form \\
\hline PRO & Pronoun \\
\hline SG & Singular \\
\hline PL & Plural \\
\hline V & Verba \\
\hline TRANS & Transitive \\
\hline INTRANS & Intransitive \\
\hline DITRANS & Ditransitive \\
\hline PRE & Preposisi \\
\hline PASS & Passive \\
\hline VLS & Valency \\
\hline
\end{tabular}




\section{Method of Analysis}

The method is a way of approaching, observing, analyzing, and explaining a phenomenon (Kridalaksana, 2001). The data analysis method used is a referential equivalent method with the basic technique of powering it to differentiate referents. According to Sudaryanto (2015) in the method of matching, the outside determinant is detached, and does not become part of the language (langue) concerned. The method is used because the thing analyzed in this article is the valency structure of the verb in the matter of Listening Comprehension practice of the TOEFL test. Matching method techniques are basic techniques and advanced techniques (Sudaryanto, 2015).

The basic technique used is the technique of determining the determinant elements by powering them to differentiate the referents. According to Sudaryanto (2015) the types of determinants will be separated or divided into various elements. The power of the sort is called the referential sorting power which then used to determine the structure and variation of the review text structure that meets the superstructure. This technique is used to sort or classify the valency structure of verbs in the matter of Listening Comprehension practice of the TOEFL test. The source of data is from The Complete Guide to the TOEFL Test written by Bruce Rogers.

\section{Discussion}

As it is discussed earlier, verb valency requires a dependent in designing sentence structure. The dependent number is very varied, so there will be found verbs with one, two and three valences.

\subsection{One-Valent Verb (Monovalency)}

A single valent or monovalency verb in a sentence or clause is a verb form which is only compounded with one dependent element and is usually the subject of that clause. This verb can also be referred to as an intransitive verb where its appearance does not require a dependent function as a grammatical object. Here is an example of one valence in the TOEFL practice questions:

\begin{tabular}{l|l|l|l}
\hline$(1)$ & She & went & to the center with her friend. \\
\hline & PRO 3 SG & V & \\
\hline & VLS & INTRANS & \\
\hline$(2)$ & They & can't leave & until the rain is stopped. \\
\hline & PRO 3 SG & V & \\
\hline & & INTRANS & \\
\hline
\end{tabular}

Verbs went and leave are intransitive verb because these verbs can only be compounded with only one element - She as it is shown in clause (1). She is a pronoun that functions as the subject of the clause. Even though the clause can be extended to She went to the center with her friend and so on, but the element to the center with her friend was not the valency of the verb went. It is similar with the element they in clause (2) - They can't leave, where the element of they is also a pronoun that functions as the subject of the clause, and this clause can also be extended to They can't leave until the rain is stopped, etc. However, it does not mean that the phrases are positioned as valency verbs leave. The phrase leave until the rain is stopped grammatically is only the complement of the speech and is not located as the valency verb.

\subsection{Two-Valent Verb (Bivalency)}

A verb with two valences is a verb that can bind two arguments at once and usually the argument is the subject and grammatical object of the sentence, and both must be attached simultaneously. A two-valent verb can also be called a bivalency verb or a transitive verb, for example, the verb read in English is a bivalency verb because grammatically the verb absolutely binds two arguments together as in the following clause example:

\begin{tabular}{l|l|l|l}
\hline (3) & The young man & reads & the book. \\
\hline & PRO 3 SG & V & \\
\hline & VLS & TRANS & VLS \\
\hline
\end{tabular}

The young man and the book valency must be attached simultaneously to the verb reads, therefore the form :

a. * The young man reads

b. * reads the book

Can be considered as incomplete and not grammatically acceptable because in form (a) there will arise a question what does the young man read? while in form (b) the question will be who reads the book? So the two forms above are not perfect because they are only supported by one valency. It is similar with the following clause found in the TOEFL practice questions: 


\begin{tabular}{l|l|l|l|l}
\hline$(4)$ & Eugene & missed & a lot of class & last week \\
\hline & PRO 3 SG & V & & \\
\hline & VLS & TRANS & VLS & \\
\hline
\end{tabular}

Eugene and a lot of class must be attached simultaneously to the verb missed, therefore the form: c. ${ }^{*}$ Eugene missed

d. * missed a lot of class

Are not a grammatically acceptable form, because it can be seen from the form (c), there will be questions about what did Eugene miss?, and (d) who missed a lot of class? So, both forms (c) and (d) cannot be considered as complete form because they are only supported by one valency. This also happens in the example of the following TOEFL practice exercise;

\begin{tabular}{l|l|l|l|l}
\hline$(5)$ & They & can park & their car & at the zoo \\
\hline & PRO 3 SG & V & & \\
\hline & VLS & TRANS & VLS & \\
\hline
\end{tabular}

The verb can park is included in the verb category with two valences which are compounded with arguments and attached directly to him, so the form:

e. *they can park

$f .{ }^{*}$ can park their car

Are not categorized as a grammatically acceptable form:

\begin{tabular}{c|l|l|l}
\hline (6) & She & is making & steady progress \\
\hline & PRO 3 SG & V & \\
\hline & VLS & TRANS & VLS \\
\hline
\end{tabular}

The verb is making is categorised as a verb with two valences which are compounded with the argument and attached simultaneously to it, so the form:

$g$. * She is making

h. *is making steady progress

Are forms that cannot be considered perfect and are not grammatically acceptable. In other case, although the questions (a) what can they park? and (b) who can park the car? are commonly used in a non-formal form of conversation, but those verb syntactically is still considered as a two-valent verb.

\subsection{Three-Valent Verbs (Trivalency)}

A three-valent verb in English depends only on the type of verb, as can be seen in the verb wrote in the clause as follow:

\begin{tabular}{l|l|l|l|l|l}
\hline$(7 \mathrm{a})$ & She & wrote & a letter & to & her friend \\
\hline & PRO 3 SG & V & & & \\
\hline & VLS & DITRANS & VLS & PREP & VLS \\
\hline \multicolumn{7}{l}{ or } & whe & wrote & her friend & a letter & \\
\hline (7b) & ShO 3 SG & V & & & \\
\hline & VLS & DITRANS & VLS & VLS & \\
\hline
\end{tabular}

Clause (7a) and clause (7b) are two grammatical structures that contain the same meaning. In clause (7a), She, is a valency that is located as a grammatical subject of the clause while the valency of a letter and her friend are arguments that function as a grammatical object namely a direct object and an indirect object connected by a preposition $(t o)$. In clause (7b), the valency position of she remains as a grammatical subject, while the valency of her friend and a letter occupy a position that exchange, and at the same time the preposition (to) is no longer needed. It also can be seen in the following example:

\begin{tabular}{l|l|l|l|l|l}
\hline$(8 a)$ & He & offered & his help & to & Darlene \\
\hline & PRO 3 SG & V & & & \\
\hline & VLS & TRANS & VLS & PREP & VLS \\
\hline or & He & offered & Darlene & his help & \\
\hline$(8 b)$ & PRO 3 SG & V & & & \\
\hline & TLS & TRANS & VLS & VLS & \\
\hline
\end{tabular}


In English, it is not all forms of verbs have three valences. The three-valent examples that appear dominantly in the TOEFL practice questions are the verbs in causative construction. The concept of causative construction is expressed by Goddard (1998) which states that causative construction is an expression in which it contains an event caused by one's actions or because something happens. Almost every language has its own way of forming or expressing causative constructions. In general, causative construction describe events that consist of (1) the causee, that causes an event to occur (causing event) and (2) the caused - the event that occurs or the result that is caused by the cause of the cause (causee) (see Shibatani 1976, Comrie, 1985 and Song, 2001). Furthermore, typologically, according to Comrie (1983), causative construction can be distinguished into:

1. morphological causative construction,

2. syntactical causative/ periphrasis construction, and

3. semantical/lexical causative construction.

Morphological causative construction is the relation between causative predicates and non-causative predicates through morphological markers. In the morphological causative construction, the verb is indicated by affixes, for example in Bahasa Indonesia : "Shinta menyenangkan bunda. The affix -kan is a marker of morphological causative construction in which the ' menyenangkan' verb has a direct effect to the object. Whaley (1997) also stated that the degree of causativity is the movement from indirect to direct. It is increased by following the order of morphological-lexical analytical causative constructions.

Syntactical causative/ periphrasis construction is a construction with two different predicates in expressing the cause and effect ideas. Peripheral causative construction, according to Whaley (1997), is a construction in which various verb forms are used to express what is generally expressed by a verb in conjunction with affixes. In English, the example of "He caused / compelled / forced me to do it, shows a construction which has a variety of verb forms, such as compelled + to do, used to indicate causes that are often referred to, therefore it is called peripheral causatives, or in other words, it is indirect cause and effect.

Semantical / lexical causative construction is the relation between the ideas of causes and ideas which are inclusive in one predicate. According to Comrie (1989) and Whaley (1997) if a lexical form that expresses causation is used at once, then the construction is lexical, for example: I killed the snake.

Syntactical causative construction / periphrasis is a construction that has a three-valent verb. In the TOEFL practice question the verb is categorized as special verb. The examples of verbs which are used are have, get make and let, as in the following example:

\begin{tabular}{l|l|l|l|l|l}
\hline (9) & Dave & had & the machanic & fix & his car \\
\hline & PRO 3 SG & V & & & \\
\hline & VLS & TRANS & VLS & V & VLS \\
\hline (10) & Jerry & got & his cousin & to cut & his hair \\
\hline & PRO 3 SG & V & & & \\
\hline & VLS & TRANS & VLS & V & VLS \\
\hline$(11)$ & Cathhy & made & her son & do & his homework \\
\hline & PRO 3 SG & V & & & \\
\hline & VLS & TRANS & VLS & V & VLS \\
\hline$(12)$ & The boss & let & us & go & home \\
\hline & PRO 3 SG & V & & & \\
\hline & VLS & TRANS & VLS & V & VLS \\
\hline
\end{tabular}

The verb have, get make and let indicate that someone causes another one to do something. When a sentence contains a causative verb, it must be understood who performs the action. As it is shown in example (9) the verb have indicates that one person asks or pays another to do something. The subject of the sentence, Dave, does not perform the action. The one who does it is the mechanic. In other words the sentence means Dave had his car fixed. In example (10) the causative verb get usually means to persuade someone to do something. In this case, again it is clear that Jerry, as the subject, is not the one who performs the action. The one who does it is his cousin. . In other words the sentence means Jerry got his hair cut. The causative verb make, in example (11) means to force someone or compel someone to do something. It is Cathy's son who is compelled to do his work. In example (12) the verb let means permit or allow. The boss, as the subject of the sentence, gives permission; we go home.

\subsection{Valency Reduction}

Valency reduction occurs as a result of one of the valences being broken because its existence in the clause is not too important or optional. Valency reduction usually occurs in passive sentences, such as;

\begin{tabular}{l|l|l}
\hline (13) & Some important details & were omitted \\
\hline & VLS & V PASS \\
\hline$(14)$ & Almost every word & was misspelled \\
\hline & VLS & V PASS \\
\hline
\end{tabular}


The valency of some important details in the example (13), and almost every word in (14), are the valences that function as the agent. The two valences are deleted because their existence in the two clauses was not really needed, so that the appearance is optional. Another example of the valency reduction in the TOEFL test exercises can be seen as follows:

\begin{tabular}{l|l|l|l|l}
\hline$(15)$ & Mobile homes & were not caounted & as permanent house & until the 1960 census. \\
\hline & VLS & V PASS & & \\
\hline
\end{tabular}

\section{Conclusion}

In TOEFL practice exercises, there are verb with one, two and three valences. A single valent or monovalent verb in a sentence or clause is a verb form which is only compounded with one dependent element and is the subject of that clause. This verb can also be referred to as an intransitive verb where its appearance does not require a dependent function as a grammatical object. Furthermore, verbs with two valences are verbs that can bind two arguments at once and usually the argument is the subject and grammatical object of the sentence, and both must be attached simultaneously. A two-valent verb can also be called a bivalent verb or a transitive verb. Meanwhile, a three-valent verb appears in a sentence or clause that has a syntactic / periphrasis causative construction.

In addition to the existence of one, two and three valency verbs in the TOEFL practice exercises, there was also a form of valency reduction. It is obtained in passive sentences which occur due to the justification of valency deletion that function as agents because their existence in the clause or sentence is only optional.

\section{References}

Comrie, B. (1983). Language universals and linguistic typology. Oxford: Basil Blackwell Publisher Limited.

Comrie, B. (1985). Causative verb formation and other verb-deriving morphology' in T . Shopen (ed.). Language Typology and Syntactic Description. Vol. 33. Cambridge: Cambridge University Press.

Comrie, B. (1989). Language universals and linguistics typology, syntax and morphology. UK: Oxford \& Cambridge USA. Goddard, C. (1998). Semantic analysis - a practical introduction. Oxford: Oxford University Press.

Hopper, P.J. \& Thompson, S. A. (1982). Syntax and semantics: Studies in transitivity. New York: Academic Press Inc, 15. Katamba, F. (1993). Morphology. London: The Macmillan Press.

Kridalaksana, H. (2001). Dictionary of linguistics. Jakarta: PT Gramedia.

McNamara, T. (2000). Language Testing. Oxford: Oxford University Press.

Setyawan, R. \& Wiraatmaja, T. (2018). The analysis of semantic and pragmatic context in TOEFL test simulation on listening section: CELTIC: A Journal of Culture, English Language Teaching, Literature \& Linguistics, 5(2): 4557 .

Shibatani, M. (1976). Syntax and semantic: The grammar of causative construction. New York: Academic Press.

Song, J.J. (2001). Linguistic typology: Morphology and syntax. London: Longman.

Sudaryanto, (2015). Methods and various language analysis techniques. Yogyakarta: Duta Discourse University.

Whaley, L.J. (1997). Introduction to Typology, The unity and diversity of language. California: Sage Publications, INC.

Van Valin, J., Robert, D. \& Randy, J.L. (2002). Syntax: Structure, meaning, and function. Cambridge: Cambridge University Press.

Verhaar, J.W.M. (2012). Asas-asas Linguistik Umum. Yogyakarta: Gajah Mada University Press. 